\title{
NEMATOIDES EM Ixora coccinea L. E SUA INTERFERÊNCIA NO DESENVOLVIMENTO DAS PLANTAS
}

\author{
VAZQUEZ, Gisele Herbst ${ }^{1}$ \\ PINTO JUNIOR, Daniel Paulo ${ }^{2}$ \\ SCOMPARIN, Ana Luíza Xavier ${ }^{3}$
}

RESUMO: Os nematoides fitoparasitas prejudicam as plantas pela ação nociva sobre o sistema radicular que, por sua vez, afeta a absorção e a translocação de nutrientes, alterando a fisiologia da planta. O objetivo nesse trabalho foi avaliar a ocorrência de nematoides em Ixora coccinea L., bem como a sua interferência no desenvolvimento da parte aérea e da raiz da planta. Foram selecionados seis locais diferentes da cidade de Santa Fé do Sul/SP que possuíam exemplares de Ixora coccinea com folhas amareladas e verdes. Amostras de solo e raízes de I. coccinea foram encaminhadas para o Laboratório de Nematologia da Universidade Estadual Paulista (UNESP/Jaboticabal/SP), das quais $100 \mathrm{~cm}^{3}$ de solo foram utilizados para extração de fitonematoides através de processamento de centrifugação e $10 \mathrm{~g}$ de raiz foram processadas em liquidificador por $20 \mathrm{seg}$ associada à flotação centrífuga. Também foram feitas as determinações de comprimento do entrenó apical, comprimento, largura, massa úmida e seca de folhas e massa úmida e seca de raiz de vinte mudas de I. coccinea, dez com as folhas amareladas e dez verdes, provenientes de viveiros comerciais de Santa Fé do Sul/SP. Concluiu-se que diferentes gêneros de nematoides são encontrados associados às plantas Ixora coccinea, como: Pratylenchus brachyurus, Tylenchorhynchus sp., Helicotylenchus dihystera, Meloidogyne sp., Radopholus sp. e Rotylenchulus reniformis, predominando Radopholus e Meloidogyne. A presença de nematoides em plantas de Ixora coccinea reduz o comprimento do entrenó apical; o comprimento, a largura e a massa úmida das folhas, além do sistema radicular, sendo responsável pelo amarelecimento de suas folhas.

Palavras-chave: Plantas ornamentais, Fitonematoides, Vermes, Nematologia.

\section{NEMATODES IN Ixora coccinea L. AND ITS INTERFERENCE IN THE DEVELOPMENT OF THE PLANT}

SUMMARY: Phytopathogenic nematodes damage plants by harmful action on the root system, which in turn affects the absorption and translocation of nutrients, altering the plant's physiology. The objective of this work was to evaluate the occurrence of nematodes in Ixora coccinea L., as well as their interference in the development of the aerial part and root of the plant. Six different locations were selected in the city of Santa Fé do Sul/SP, that had Ixora coccinea with yellowish and green leaves. Samples of soil and roots of I. coccinea were taken to the Nematology Laboratory of the Universidade Estadual Paulista (UNESP/Jaboticabal/SP), of which $100 \mathrm{~cm}^{3}$ of soil were used to extract phytonmatoids through centrifugation processing and $10 \mathrm{~g}$ of root were processed in a blender for $20 \mathrm{sec}$ associated with centrifugal flotation. Apical internode, length, width, wet and dry mass of leaves and wet and dry mass of root determinations were also made for twenty seedlings of I. coccinea, ten with yellowish leaves and ten green, from commercial nurseries in Santa Fé do Sul/SP. It was concluded that different genera of nematodes are found associated with the Ixora coccinea plants, among them: Pratylenchus brachyurus, Tylenchorhynchus sp., Helicotylenchus dihystera, Meloidogyne sp., Radopholus sp. and Rotylenchulus reniformis, with Radopholus and Meloidogyne predominating. The presence of nematodes in Ixora coccinea plants reduces the length of the apical internode; the length, width and wet mass of the leaves, in addition the root system, being responsible for the yellowing of its leaves.

Keywords: Ornamental plants, Phytonematoids, Worms, Nematology.

\footnotetext{
${ }^{1}$ Enga. Agrônoma, Dra., Professora-pesquisadora do curso de Pós-Graduação em Ciências Ambientais e de Graduação em Agronomia- Universidade Brasil- Fernandópolis-SP

${ }^{2}$ Engenheiro Agrônomo pela Universidade Brasil - Fernandópolis -SP

${ }^{3}$ Enga. Agrônoma, Dra., Professora do curso de Graduação em Agronomia- Unilago- São José do Rio Preto-SP
} 


\section{INTRODUÇÃO}

O Brasil tem grandes chances de se tornar um significativo produtor e exportador de flores e plantas ornamentais no cenário mundial, porém há desafios a serem vencidos e que representam a utilização da aplicação de tecnologias avançadas nos sistemas de produção, uso de material genético adequado, treinamento e capacitação da mão de obra, profissionalismo nas áreas gerencial, comercial, de logística e distribuição, explorações das aptidões regionais, organização das estruturas comerciais e incentivos a tecnologias de embalagem e pós-colheita (SALOMÉ, 2007).

Em São Paulo, a produção de flores e plantas ornamentais evoluiu consideravelmente nas últimas décadas, passando a ser reconhecida como uma atividade de importância econômica.

A Ixora coccinea é uma planta nativa da Índia e Sri Lanka, típica de regiões de clima tropical e subtropical, que chega a atingir até dois metros de altura. Pertence a família das Rubiaceae, sendo conhecida cerca de 400 espécies. Por produzirem flores quase que o ano todo, é muito utilizada na ornamentação de praças e jardins. Deve ser cultivada sempre a pleno sol, e não é muito exigente em fertilidade, sendo bastante rústica, multiplica-se por estacas e não tolera geadas. Dispensa maiores manutenções, mas deve ser regada a intervalos regulares (BLOSSFELD, 1965). Pode ser cultivada isoladamente ou em maciços, sendo adequadas para esconder muros e muretas. É uma planta muito comum, sendo conhecida popularmente por diversos nomes como Cruz de Malta, Amor Ardente, Ixora vermelha, entre outros (JARDINEIRO, 2007).

Nos últimos anos, tem sido observado um aumento na ocorrência de pragas e doenças em plantas ornamentais, especialmente fungos e nematoides, em decorrência do crescimento das áreas de produção no Brasil (LINS; COELHO, 2004). De acordo com Oliveira e Kubo (2006), mais de 30 espécies de nematoides associados a plantas ornamentais já foram relatadas em cultivos de casa-de-vegetação, muito embora algumas não tiveram patogenicidade comprovada. Ainda segundo os mesmos autores, além dos danos diretos que os nematoides causam às plantas, tal associação pode trazer sérios problemas na implantação de jardins, gramados e áreas de reflorestamento, em propriedades agrícolas, uma vez que essas plantas podem servir como fonte de inóculo.

Os nematoides fitoparasitas prejudicam as plantas pela ação nociva sobre o sistema radicular que, por sua vez, afeta a absorção e a translocação de nutrientes, alterando a fisiologia da planta. Esses organismos também podem predispor a planta a doenças e a estresses ambientais ou atuarem como transmissores de outros patógenos (GOMES; CAMPOS, 2003).

Alimentando-se das plantas, os nematoides causam danos que podem ser expressos pela redução de produção ou então pela depreciação da qualidade do produto a ser comercializado. 
Além disso, na tentativa de minimizar o prejuízo e controlar o nematoide, o agricultor tem gastos adicionais com fertilizantes, defensivos e outras práticas. Embora poucas espécies apresentem patogenicidade comprovada, os nematoides das galhas radiculares (Meloidogyne spp.), os nematoides das lesões radiculares (Pratylenchus spp.), o nematoide cavernícola (Radopholus similis) e os nematoides de parte aérea (Aphelenchoides spp.) são responsáveis pelos maiores prejuízos econômicos (OLIVEIRA; KUBO, 2006).

As espécies Meloidogyne javanica e M. incognita, além de M. arenaria e M. hapla são as mais importantes do gênero Meloidogyne associadas às plantas ornamentais. O gênero Meloidogyne são endoparasitos sedentários e o sintoma típico de sua presença em plantas ornamentais são as galhas radiculares, que são engrossamentos das raízes devido ao aumento de tamanho das células do córtex (hipertrofia celular) e/ou, do aumento do número de células (hiperplasia celular). Devido a sua presença, o sistema radicular torna-se ineficiente na absorção de água e nutrientes e, as plantas mostram-se pouco vigorosas e pequenas. As folhas podem ficar com tamanho menor e coloração anormal, semelhantes a sintomas de deficiência nutricional. Finalmente, ocorre diminuição na produção, inviabilizando a exploração econômica (OLIVEIRA; KUBO, 2006).

Os nematoides do gênero Pratylenchus frequentemente causam ferimentos nas raízes das plantas por meio dos quais outros organismos patogênicos, como bactérias e fungos, penetram e são considerados o segundo de importância no Brasil. A interação desses agentes resulta na formação de lesões que finalmente destroem os tecidos radiculares. As plantas tornam-se pequenas, com ramos finos, devido à completa destruição das raízes e radicelas. A parte aérea de plantas afetadas pode apresentar clorose ou murchamento durante a estação seca. A desfolha total pode ocorrer quando o ataque é severo. A ação do nematoide pode ser percebida ao se comparar a raiz de uma planta atingida com outra saudável. A doente fica escura e mais curta, enquanto a sadia é mais clara e longa. Suas espécies são polífagas, parasitando uma ampla gama de hospedeiros, principalmente gramíneas (arroz, trigo, cana-de-açúcar, milho e forrageiras), algodão, soja, café, citros, fumo, batata, algumas olerícolas, ornamentais, essências florestais e sobrevive em diversas plantas daninhas (KIMATI et al., 2005; GOULART, 2008).

O gênero Radopholus inclui cerca de vinte espécies e apenas uma $-R$. similis - é considerada de grande importância econômica ao redor do mundo, como parasita comum de musáceas, principalmente de bananeiras, sendo denominado nematoide cavernícola. A estratégia de alimentação é quase idêntica à das espécies de Pratylenchus. O R. similis causa galerias ou cavernas no interior das raízes e o problema é agravado pela penetração de fungos e bactérias pelas aberturas nas raízes promovidas pelo nematoide. Em geral, devido à destruição do sistema radicular, as plantas apresentam crescimento deficiente, podendo eventualmente, como relatado 
em bananeiras, apresentar a parte aérea com clorose e reducão na produção. No Brasil, em bananais em que o nematoide cavernícola está presente também ocorre a espécie Helicotylenchus multicinctus. O nematoide cavernícola não é nativo do país e, portanto, só estará presente em solos nos quais tenha sido ou venha a ser inadvertidamente introduzido (FERRAZ; BROWN, 2016).

O gênero Tylenchorhynchus contém mais de 100 espécies descritas que parasitam uma grande variedade de plantas (soja, tabaco, aveia, sorgo, rosa, alface, uva, citros, milho, arroz, tomate, entre outras). Normalmente são nematoides de solo e afetam o sistema radicular do hospedeiro, sendo os danos apresentados por sua incidência a descoloração da raiz e do caule, danos na casca e clorose nas folhas. Uma vez danificadas, as plantas ficam expostas a incidência de parasitas secundários (DEFESAVEGETAL.NET, 2017).

O nematoide reniforme (Rotylenchulus reniformis) é um importante patógeno radicular, sendo relatado no Brasil associado às culturas de melão, maracujá, tomate, soja e algodão. Foi durante muito tempo considerado de importância secundária, por ausência de sintomas nas plantas infectadas. O $R$. reniformis é um semi-endoparasita sedentário típico que, após a penetração nas raízes permanece com mais de dois terços da parte posterior do corpo para o exterior. Com a evolução do parasitismo, a fêmea aumenta de volume, adquirindo o formato de um rim, característica que origina a denominação "reniforme". Plantas parasitadas por $R$. reniformis apresentam-se subdesenvolvidas, mantendo a cor normal. Os sintomas podem ser confundidos com problemas de compactação de solo, encharcamento, ou mesmo de carência nutricional. As raízes não mostram sintomas claros. Apenas em laboratório é possível, com clareza, observar as fêmeas do nematoide nas raízes (ASMUS, 2008).

Os fitonematoides espiralados (Helicotylenchus spp.), já foram observados atacando diversas espécies agrícolas no Brasil, sendo considerado um ectoparasita e endoparasita migratório. O patógeno penetra preferencialmente nas raízes mais grossas, onde causa a formação de pequenas lesões com inúmeras pontuações superficiais de coloração acastanhada. Quando a população de nematoides é grande, as lesões podem coalescer, resultando em necrose da superfície da raiz. Ele pode sobreviver por vários meses no solo sem a presença da planta hospedeira e seu ciclo de vida varia de 35 a 37 dias à temperatura de $23-33^{\circ} \mathrm{C}$. A umidade compreendida entre 40 e $60 \%$ da capacidade de campo é considerada ótima, mas em solos secos, as mais altas populações são encontradas. O sucesso do controle em áreas infestadas depende de um conjunto de medidas associadas, visando principalmente reduzir o nível populacional e impedir a sua multiplicação. Recomenda-se a utilização de mudas sadias e a limpeza das ferramentas e máquinas agrícolas antes de executar trabalhos nas áreas ainda não infestadas. Recomenda-se também a adubação verde nas entrelinhas, utilizando plantas que inibem a 
reprodução, e a eliminação das plantas daninhas hospedeiras dos nematoides (GARBIN; COSTA, 2015).

O reconhecimento de espécies e gêneros de fitonematoides numa cultura é de grande importância para se formar um acervo de dados que são úteis nos laboratórios de diagnose e controle desses patógenos. Assim, o objetivo nesse trabalho foi avaliar a ocorrência de nematoides em plantas de Ixora coccinea L., bem como a sua interferência no desenvolvimento da parte aérea e da raiz.

\section{MATERIAL E MÉTODOS}

O município de Santa Fé do Sul situa-se a $20^{\circ} 12^{\prime} 71^{\prime}$ de latitude Sul e a $50^{\circ} 55^{\prime} 51^{\prime}$ de longitude W Gr. e a altitude é de 380 m, possui área de 208,3 km², população estimada de 32.322 pessoas em 2019 e está localizado no extremo noroeste do estado de São Paulo, distante 624 km da capital por rodovia, e seu clima é tropical com inverno seco (IBGE, 2020).

Inicialmente, no dia 20/10/2016 foram amostrados seis pontos da cidade de Santa Fé do Sul/SP que continham canteiros com exemplares de ixora com folhas amareladas e verdes (Figura $1)$.

Figura 1: Plantas de ixora com folhas amareladas em um dos pontos amostrados na cidade de Santa Fé do Sul/SP.

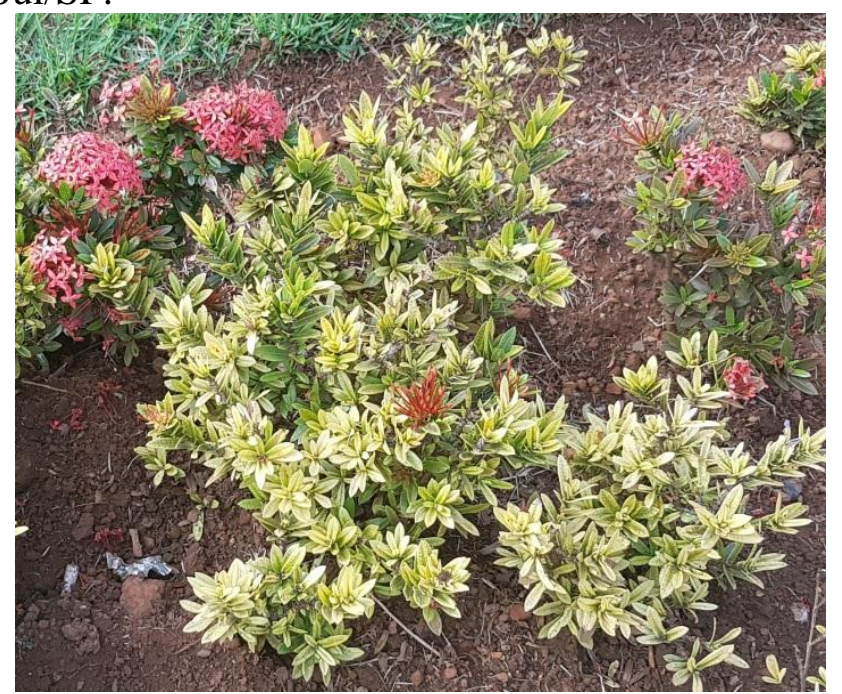

Fonte: Arquivo pessoal, 2016.

O procedimento para a amostragem foi efetuado com o auxílio de uma pá reta que foi introduzida a 15-20 cm de profundidade na projeção da copa das plantas, retirando-se em cada ponto diversas frações que foram homogeneizadas. Portanto, após o corte da parte aérea das plantas, em cada ponto de amostragem, foram retiradas frações de solo e de raízes com solo de 
seis plantas com folhas amareladas e seis verdes, totalizando 12 amostras, que foram colocadas em sacos plásticos e identificadas.

As amostras foram encaminhadas ao Laboratório de Nematologia da Universidade Estadual Paulista (UNESP/Jaboticabal/SP) e a análise realizada no dia 21/10/2016.

Para a extração de nematoides do solo $\left(100 \mathrm{~cm}^{3}\right)$, utilizou-se a técnica do peneiramento, seguida de centrifugação em solução de sacarose (JENKINS, 1964). Os nematoides endoparasitas foram extraídos por metodologia proposta por Hussey e Barker (1973), modificada por Boneti e Ferraz (1981), mediante trituração de raízes (10 g) em liquidificador com uma solução de hipoclorito de sódio por $20 \mathrm{seg}$. Em seguida, os nematoides foram separados dos resíduos radiculares pela técnica proposta por Coolen e D’Herde (1972), utilizando-se centrifugação.

Procedeu-se à identificação dos nematoides pela montagem dos espécimes em lâminas semipermanentes e pelo uso de chaves de classificação atualizadas.

Além disso, foram selecionadas dez mudas de ixora desenvolvidas em sacos plásticos com as folhas amareladas e outras dez, sem o sintoma (Figura 2). As mudas foram provenientes de um viveiro comercial de Santa Fé do Sul/SP e possuíam cerca de um ano.

Figura 2: Plantas de ixora com e sem folhas amareladas (A) provenientes de viveiros comerciais de Santa Fé do Sul/SP. Detalhe da folha amarelada (B)

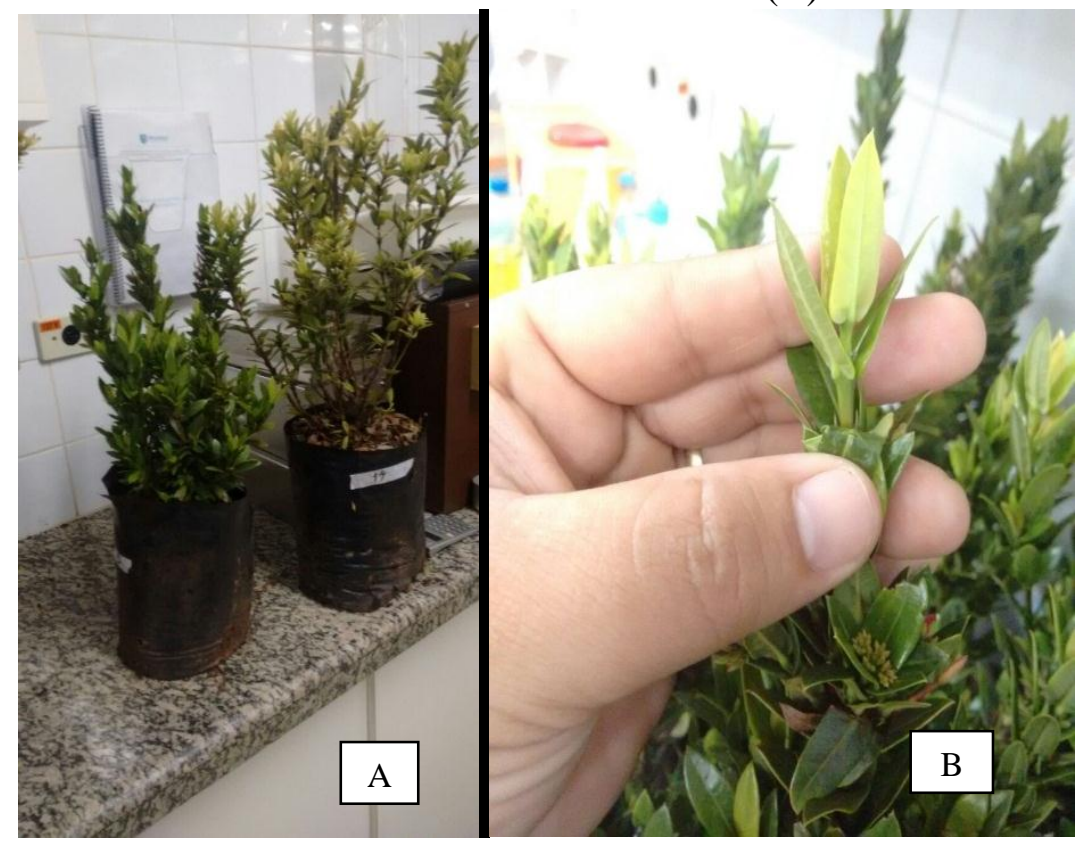

Fonte: Arquivo pessoal, 2016.

A biometria das plantas foi realizada no Laboratório de Agricultura da Universidade Brasil, campus Fernandópolis/SP e de cada amostra de plantas, ou seja, amarelada e não amarelada, foram determinadas as seguintes variáveis: 
- comprimento do entrenó apical com o uso de um paquímetro (mm): realizada em 10 locais diferentes de cada planta.

- comprimento e largura da folha com o uso de uma régua graduada $(\mathrm{cm})$ : realizado em 10 folhas de cada planta (Figura 3A).

- massa úmida e seca das folhas e do sistema radicular com o uso de uma balança de precisão: após a medição das folhas, as mesmas foram pesadas obtendo-se a massa úmida e em seguida foram secadas em estufa a $65^{\circ} \mathrm{C}$ por $96 \mathrm{~h}$. Para a determinação da massa do sistema radicular, retirou-se a terra contida nos sacos plásticos e com água separou-se as raízes que foram pesadas da mesma forma que as folhas (Figura 3B).

Figura 3: Determinação do comprimento do entrenó apical de plantas de ixora (A). Sistema radicular úmido das plantas verdes (esquerda) e amareladas (direita) de ixora (B), Fernandópolis/SP.

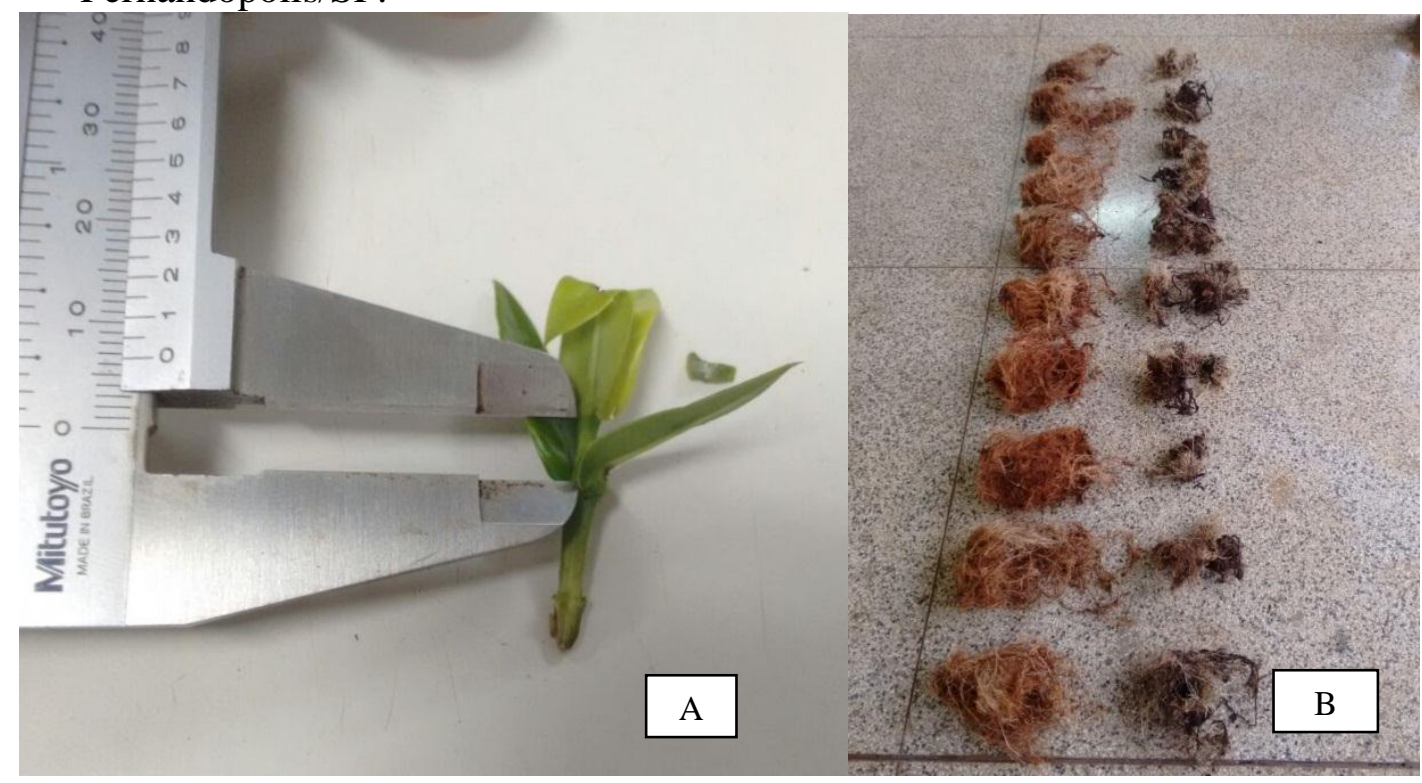

Fonte: Arquivo pessoal, 2016.

Para a análise estatística foi utilizado o programa SISVAR (FERREIRA, 2014). A comparação entre as médias foi realizada pelo teste de Tukey a 5\%.

\section{RESULTADOS E DISCUSSÃO}

Os seguintes nematoides foram identificados: Pratylenchus brachyurus, Tylenchorhynchus sp., Meloidogyne sp., Radopholus sp., Rotylenchulus reniformis e Helicotylenchus dihystera (Tabela 1).

Nas raízes de plantas com folhas amareladas foram encontrados todos os nematoides descritos anteriormente, com exceção do Rotylenchulus reniformis, que como relatado Asmus (2008), não afeta a coloração das folhas. Destaca-se a presença de 4920 nematoides da espécie 
Radopholus sp. em $100 \mathrm{~cm}^{3}$ de solo em plantas amareladas no local denominado Rancho (Tabela 1). Sabe-se que o Radopholus causa galerias ou cavernas no interior das raízes, destruindo o sistema radicular, fazendo com que as plantas apresentem um crescimento deficiente (FERRAZ; BROWN, 2016).

Em raízes de plantas verdes, também foram identificadas todas as seis espécies de nematoides descritas.

Tabela 1: Nematoides associados a plantas de Ixora coccinea com folhas verdes e amareladas extraídos em $100 \mathrm{~cm}^{3}$ de solo e dez gramas de raiz, em Santa Fé do Sul/SP, 2016.

\begin{tabular}{|c|c|c|c|c|c|c|c|c|c|c|c|c|c|}
\hline \multirow[t]{2}{*}{ Local } & \multirow[t]{2}{*}{ Cor } & \multicolumn{2}{|c|}{ Pratylenchus } & \multicolumn{2}{|c|}{ Tylenchorhynchus } & \multicolumn{2}{|c|}{ Meloidogyne } & \multicolumn{2}{|c|}{ Radopholus } & \multicolumn{2}{|c|}{ Rotylenchulus } & \multicolumn{2}{|c|}{ Helicotylenchu } \\
\hline & & Solo & Raiz & Solo & Raiz & Solo & Raiz & Solo & Raiz & Solo & Raiz & Solo & Raiz \\
\hline \multirow{2}{*}{$\begin{array}{c}\text { Centro } \\
\text { olímpico }\end{array}$} & $\mathrm{V}$ & 0 & 0 & 0 & 0 & 0 & 0 & 0 & 0 & 0 & 0 & 0 & 8 \\
\hline & A & 4 & 4 & 0 & 0 & 0 & 0 & 0 & 0 & 0 & 0 & 4 & 8 \\
\hline \multirow{2}{*}{$\begin{array}{c}\text { Vale do } \\
\text { Sol } \\
\end{array}$} & $\mathrm{V}$ & 0 & 0 & 36 & 0 & 0 & 0 & 0 & 0 & 0 & 0 & 0 & 0 \\
\hline & A & 16 & 132 & 0 & 0 & 0 & 0 & 0 & 0 & 0 & 0 & 0 & 4 \\
\hline \multirow{2}{*}{$\begin{array}{l}\text { Área de } \\
\text { banana }\end{array}$} & $\mathrm{V}$ & 4 & 4 & 0 & 0 & 0 & 0 & 0 & 0 & 196 & 20 & 0 & 0 \\
\hline & A & 0 & 0 & 0 & 16 & 0 & 0 & 0 & 0 & 0 & 0 & 0 & 0 \\
\hline \multirow{2}{*}{ Rancho } & $\mathrm{V}$ & 0 & 0 & 16 & 0 & 200 & 72 & 0 & 0 & 0 & 0 & 0 & 0 \\
\hline & A & 0 & 0 & 20 & 0 & 0 & 0 & 24 & 4920 & 0 & 0 & 0 & 0 \\
\hline \multirow{2}{*}{$\begin{array}{c}\text { Praça } \\
\text { Bela } \\
\text { Vista }\end{array}$} & $\mathrm{V}$ & 0 & 0 & 0 & 0 & 4 & 4 & 0 & 28 & 0 & 0 & 0 & 0 \\
\hline & A & 0 & 0 & 12 & 20 & 4 & 0 & 0 & 4 & 0 & 0 & 0 & 8 \\
\hline $\begin{array}{c}\text { Av. } \\
\text { Navarro }\end{array}$ & $\mathrm{V}$ & 0 & 0 & 12 & 52 & 0 & 0 & 0 & 0 & 0 & 0 & 8 & 0 \\
\hline Andrade & A & 0 & 0 & 0 & 0 & 124 & 80 & 0 & 0 & 0 & 0 & 40 & 0 \\
\hline
\end{tabular}

Fonte: Elaborada pelos autores

Em relação à quantidade total de nematoides no solo e nas raízes de ixora, foram contabilizadas 664 e 5444 unidades em plantas verdes e amareladas, respectivamente. Já quanto as espécies encontradas, os seguintes resultados foram obtidos: Pratylenchus brachyurus (164 unidades), Tylenchorhynchus sp. (184 unidades), Meloidogyne sp. (488 unidades), Radopholus sp. (4976 unidades), Rotylenchulus reniformis (216 unidades) e Helicotylenchus dihystera (80 unidades).

Oliveira (2001) também relatou a presença de Meloidogyne incognita em plantas de Ixora finlaysoniana. O nematoide das galhas, gênero Meloidogyne, é considerado o mais importante dentre os fitonematoides em razão das elevadas perdas provocadas em áreas de exploração agrícola em todo o mundo (SILVA et al., 2016). Porém, em mudas comercializadas nas regiões norte e noroeste do Paraná, Dias-Arieira et al. (2007) não constataram nenhum nematoide fitoparasito nas amostras de raízes de Ixora coccinea, apesar da presença de 42 nematoides de vida livre (Pratylenchus) em $100 \mathrm{~cm}^{3}$ de solo nessas amostras. Já na Nigéria foi feita uma 
avaliação de dezesseis plantas ornamentais quanto à resistência a infecção causada por Meloidogyne incognita em casa de vegetação, e a Ixora ccoccinea foi clasificada como moderadamente a altamente suscetível (SALAWU; DARABILAN, 2010). Giblin-Davis et al. (1992) avaliaram a suscetibilidade de diferentes variedades de ixora a algumas populações de Meloidogyne e constataram que as variedades de I. coccinea comportam-se de forma variável frente às populações dos nematoides de galha. As cultivares Bonnie Lynn, Maui e Petite Red comportaram-se como boas hospedeiras de $M$. incognita raça 1, mas não hospedeira de $M$. javanica; por outro lado, Singapore e Petite Yellow não foram boas hospedeiras de $M$. incognita raça 1, mas foram excelentes hospedeiras de M. javanica.

As espécies do gênero Meloidogyne são os principais nematoides relatados na literatura e foram considerados pragas graves em plantas ornamentais em muitas regiões do mundo, causando crescimento clorótico e atrofiado, com folhas e flores em menor quantidade e tamanho, número excessivo de galhas nas raízes e, eventualmente, a morte (RATHOUR et al., 2003; TARIQ et al., 2007).

Costa et al. (2003) coletaram amostras de solo e/ou raízes de 56 plantas ornamentais e floríferas do câmpus da Universidade Federal de Lavras (UFLA/MG), e observaram as seguintes frequências de fitonematoides nas amostras: Helicotylenchus dihystera (19,7\%), Meloidogyne incognita (16,7\%), Xiphinema brasiliensi (10,61\%), Meloidogyne spp. (9,09\%), Ogma sp. (7,58\%), Trichodorus sp. (7,58\%), Meloidogyne javanica (7,58\%), Criconemella ornata (4,55\%), Tylenchorrynchus sp. (4,55\%), Aphelenchus sp. (3,03\%), Xiphinema spp. (3,03\%), Aphelenchus avenae (1,52\%), Tylenchulus semipenetrans (1,52\%), Dorilaimus sp. (1,52\%) e Ditylenchus sp. $(1,52 \%)$.

Dias-Arieira et al. (2007) realizaram em 38 espécies de plantas ornamentais um levantamento de nematoides associados a raízes, solo e substrato em mudas comercializadas nas regiões norte e noroeste do Paraná. Nas 114 amostras examinadas, Helicotylenchus spp. ocorreu em 35,1\%, Tylenchus spp. em 16,7\%, Meloidogyne spp. e Paratylenchus spp. em 14,9\%, Mesocriconema spp. em 12,3\%, tricodorídeos em 8,8\% e Pratylenchus spp. em 5,3\%. Os nematoides dos gêneros Rotylenchulus, Xiphinema, Aorolaimus e Hoplolaimus ocorreram em baixa frequência.

Já a análise da biometria das plantas de ixora mostrou que em todas as variáveis analisadas, as plantas com folhas verdes superaram estatisticamente as com folhas amareladas, com exceção de massa seca de folhas (Tabela 2). 
Tabela 2: Valores do comprimento do entrenó apical; comprimento, largura, massa úmida e seca das folhas e massa úmida e seca do sistema radicular de plantas de Ixora coccinea provenientes de plantas com folhas verdes e amareladas. Santa Fé do Sul/SP, 2016.

\begin{tabular}{lccccccc}
\hline $\begin{array}{l}\text { Cor das } \\
\text { folhas }\end{array}$ & $\begin{array}{c}\text { Comprimento } \\
\text { do entrenó }\end{array}$ & $\begin{array}{c}\text { Comprim. } \\
\text { da folha }\end{array}$ & $\begin{array}{c}\text { Largura } \\
\text { da folha }\end{array}$ & $\begin{array}{c}\text { MU } \\
\text { folha }\end{array}$ & $\begin{array}{c}\text { MS } \\
\text { folha }\end{array}$ & $\begin{array}{c}\text { MU } \\
\text { raiz }\end{array}$ & $\begin{array}{c}\text { MS } \\
\text { Raiz }\end{array}$ \\
\cline { 2 - 8 } & $\mathbf{m m}$ & $\mathbf{c m}$ & $\mathbf{C m}$ & $\mathbf{g}$ & $\mathbf{g}$ & $\mathbf{g}$ & $\mathbf{G}$ \\
\hline Verde & $8,12 \mathrm{a}$ & $3,56 \mathrm{a}$ & $1,10 \mathrm{a}$ & $4,11 \mathrm{a}$ & $0,329 \mathrm{a}$ & $272,43 \mathrm{a}$ & $137,70 \mathrm{a}$ \\
Amarelada & $3,15 \mathrm{~b}$ & $3,11 \mathrm{~b}$ & $0,98 \mathrm{~b}$ & $3,95 \mathrm{~b}$ & $0,313 \mathrm{a}$ & $131,84 \mathrm{~b}$ & $48,70 \mathrm{~b}$ \\
\hline CV (\%) & 10,84 & 3,34 & 7,58 & 2,89 & 19,26 & 44,77 & 57,8 \\
\hline
\end{tabular}

Letras iguais na mesma coluna não diferem entre si pelo teste de Tukey a 5\% de probabilidade.

Fonte: Elaborada pelos autores

Em termos numéricos, as plantas com folhas verdes apresentaram valores 157,7\%, 14,5\%, $12,2 \%, 4,0 \%, 5,1 \%, 106,6 \%$ e $182,7 \%$ maiores que as plantas com folhas amareladas em relação ao comprimento do entrenó apical, comprimento e largura das folhas, massa úmida e seca das folhas e massa úmida e seca do sistema radicular, respectivamente. Destaca-se a grande diferença dos resultados quanto a massa seca do sistema radicular, onde os valores das plantas com folhas verdes foi quase três vezes superior em relação às amareladas. Os gêneros Radopholus, Pratylenchus e Meloidogyne destroem o sistema radicular, interferindo no desenvolvimento das plantas, fato este também relatado por Goulart, (2008); Oliveira \& Kubo (2006) e Ferraz \& Brown (2016) em suas pesquisas.

O controle de nematoides parasitos de plantas ornamentais é provavelmente uma das atividades que mais desafiam os produtores, não havendo registros de nematicidas recomendados para plantas ornamentais no Brasil, com exceção do uso de fenamifós no tratamento de marantas infestadas com Radopholus similis (BARBOSA et al., 1990), sendo o controle biológico uma boa alternativa.

De forma geral, devido às limitações do controle curativo, as medidas preventivas são preconizadas, incluindo-se entre elas, o uso de mudas isentas de nematoides e plantio em solo ou substrato não infestado.

\section{CONCLUSÃO}

Diferentes gêneros de nematoides foram encontrados associados às plantas Ixora coccinea (Pratylenchus brachyurus, Tylenchorhynchus sp., Helicotylenchus dihystera, Meloidogyne sp., Radopholus sp. e Rotylenchulus reniformis), predominando os gêneros Radopholus e Meloidogyne.

A presença de nematoides em plantas de Ixora coccinea reduz o comprimento do entrenó apical; o comprimento, a largura e a massa úmida das folhas, além de interferir no desenvolvimento do sistema radicular, sendo responsável pelo amarelecimento das folhas. 


\section{REFERÊNCIAS}

ASMUS, G. L. Ocorrência e manejo do nematoide reniforme em Mato Grosso do Sul. EMBRAPA Agropecuária Oeste, 2008. 3 p.

BARBOSA, L. J.; BENATTI, A. M.; SALVO, S. Estudo da eficiência de nematicida para o controle de Radopholus similis (Cobb, 1893) na cultura da maranta, Calathea zebrina (Maranta zebrina). Ecossistema, Espírito Santo do Pinhal, v. 15, p. 160-66, 1990.

BLOSSFELD, H. Jardinagem. São Paulo: Melhoramentos, 1965. 415 p.

BONETI, J. I. S.; FERRAZ, S. Modificação do método de Hussey e Barker para extração de ovos de Meloidogyne exigua do cafeeiro. Fitopatologia Brasileira, Brasília, v. 6, n. 3, p. 553, out. 1981.

COOLEN, W. A.; D'HERDE, C. J. A method for the quantitative extration of nematodes from plant tissue. Ghent: Nematology and Entomology Research Station, 1972. 77 p.

COSTA, M. J. N., COELHO, S. J.; CAMPOS, V. P. Nematoides em plantas ornamentais e floríferas em Lavras (MG). Rev. Bras. Hortic. Ornam., Campinas, v. 9, n. 2, p. 183-186, 2003.

DEFESAVEGETAL.NET. Novo nematoide em soja. 2017. Disponível em: http://www.defesavegetal.net/single-post/2018/01/23/Novo-nematoide-em-soja. Acesso em: 10 jan. 2020.

DIAS-ARIEIRA, C. R.; MORITA, D. A. S.; MACHADO, M. H. Nematoides associados a plantas ornamentais em viveiros do Paraná. Nematologia Brasileira, Piracicaba, v. 31, n. 1, p. 46-55, 2007.

FERRAZ, L. C. C. B.; BROWN, D. J. F. (Orgs.). Nematologia de plantas: fundamentos e importancia. Manaus: NORMA EDITORA, 2016. 251 p.

FERREIRA, D.F. Sisvar: A Guide for its Bootstrap procedures in multiple comparisons. Ciência \& Agrotecnologia, v.38, n.2, p.109-112, 2014.

GARBIN, L. F.; COSTA, M. J. N. Incidência do fitonematoide Helicotylenchus em analises laboratoriais do Mato Grosso. Revista Connection Line, n. 12, p. 90-96, 2015.

GIBLIN-DAVIS, R. M., MEEROW, A. W.; BILZ, F. G. Host suitability of Ixora spp. for the root-knot nematodes Meloidogyne incognita raça 1 e M. javanica. Journal of Nematology, v. 24, n. 4S, p. 722-728, 1992.

GOMES, C. B.; CAMPOS, A. D. Sistema de produção de pêssego de mesa na região da Serra Gaúcha. 2003. Disponível em:

http://www.cnpuv.embrapa.br/publica/sprod/PessegodeMesaRegiaoSerraGaucha/nemato.htm.

Acesso em: 20 ago. 2019.

GOULART, A. M. C. Nematoides das lesões radiculares (Gênero Pratylenchus).

2008. Disponível em: http://www.agrosoft.org.br/agropag/103613.htm. Acesso em: 30 set. 2019.

HUSSEY, R. S.; BARKER, K. R. A comparison of methods for colecting inocula of Meloidogyne spp. including a new technique. Plant Disease Reporter, Washington, v. 57, n. 12, p. 1025-1028, Dec. 1973. 
IBGE - Instituto Brasileiro de Geografía e Estatística. Cidades. 2020. Disponível em: https://cidades.ibge.gov.br/brasil/sp/santa-fe-do-sul/panorama. Acesso em: 06 jan. 2020.

JARDINEIRO. 2007. Disponível em: http://www.jardineiro.net/br/banco/ixora_coccinea.php . Acesso em: 12 fev. 2019. Acesso em: 30 set. 2019.

JENKINS, W. R. A rapid centrifugal-flotation technique for separating nematodes from soil.

Plant Disease Reporter, Washington, v. 48, n. 9, p. 692, Sept. 1964.

KIMATI, H.; AMORIM, L.; RESENDE, J. A. M.; BERGAMIN FILHO, A.; CAMARGO, L. E. A. (Ed.). Manual de fitopatologia: doenças das plantas cultivadas. 4 ed. São Paulo: Agronômica Ceres, 2005. v. 2, 663 p.

LINS, S. R. O.; COELHO, R. S. B. Ocorrência de doenças em plantas ornamentais tropicais no Estado de Pernambuco. Fitopatologia Brasileira, v. 29, n. 3, p. 332-335, 2004.

OLIVEIRA, C. M. G. Nematoides parasitos de plantas. In: IMENES, S. L; ALEXANDRE, M. A. V. (Eds.). Pragas e doenças em plantas ornamentais. São Paulo: Instituto Biológico, 2001. p. 38-47. CD-ROM (ISBN 85-88694-01-8).

OLIVEIRA, C. M. G.; KUBO, R. K. Nematoides parasitos de plantas ornamentais. In: REUNIÃO ITINERANTE DE FITOSSANIDADE DO INSTITUTO BIOLÓGICO, XIV (Plantas Ornamentais), Pariquera-Açu/SP. Anais..., Pariquera-Açu/SP, 2006, p. 27-33.

RATHOUR, K. S.; SHARMA, S.; GANGULY, S. Phytonematode communities associated with perennial ornamental and medicinal plants in Bareilly District, Uttar Pradesh. In: NATIONAL SYMPOSIUM ON BIODIVERSITY AND MANAGEMENT OF NEMATODES IN CROPPING SYSTEMS FOR SUSTAINABLE AGRICULTURE, 11-13 november 2002, Jaipur, India. Proceedings..., Jaipur, India, 2003, p. 31-38.

SALAWU, E. O.; DARABIDAN, I. A. Screening of selected ornamental plants to Meloidogyne incognita in Nigeria. Pak. J. Nematol, Nigéria, v. 28, n. 2, p.353-358, 2010.

SALOMÉ, J. R. Mercado brasileiro de flores e plantas ornamentais. 2007. Disponível em: http://www.aptaregional.sp.gov.br/artigo.php?id_artigo=511. Acesso em: 17 dez. 2019.

SILVA, M. do C. L. da; SANTOS, C. D. G.; SILVA, G. S. da. Espécies de Meloidogyne associadas a vegetais em microrregiões do estado do Ceará. Rev. Ciênc. Agron., Fortaleza, v. 47, n. 4, p. 710-719, 2016.

TARIQ, M.; FIROZA, K.; SHAHINA, F. Medicinal plants as new hosts of rootknot and other nematodes from Hamdard University, Karachi, Pakistan. Pakistan J. Nematol. v. 25, n. 1, p. 165-172, 2007. 